\title{
Endoscopic versus microscopic microvascular decompression for trigeminal neuralgia: equivalent pain outcomes with possibly decreased postoperative headache after endoscopic surgery
}

\author{
John Y. K. Lee, MD, MSCE, John T. Pierce, MS, Sukhmeet K. Sandhu, MD, Dmitriy Petrov, MD, and \\ Andrew I. Yang, MD, MS \\ Department of Neurosurgery, University of Pennsylvania, Philadelphia, Pennsylvania
}

OBJECTIVE Endoscopic surgery has revolutionized surgery of the ventral skull base but has not yet been widely adopted for use in the cerebellopontine angle. Given the relatively normal anatomy of the cerebellopontine angle in patients with trigeminal neuralgia (TN), the authors hypothesized that a fully endoscopic microvascular decompression (E-MVD) might provide pain outcomes equivalent to those of microscopic MVD (M-MVD) but with fewer complications.

\begin{abstract}
METHODS The authors conducted a single-institution, single-surgeon retrospective study with patients treated in the period of 2006-2013. Before surgery, all patients completed a questionnaire that included a validated multidimensional pain-outcome tool, the Penn Facial Pain Scale (PFPS, formerly known as Brief Pain Inventory-Facial), an 11-point scale that measures pain intensity, interference with general activities of daily living (ADLs), and facial-specific ADLs. Using a standardized script, independent research assistants conducted follow-up telephone interviews.
\end{abstract}

RESULTS In total, 167 patients were available for follow-ups (66.5\% female; 93 patients underwent M-MVD and 74 underwent E-MVD). Preoperative characteristics (i.e., TN classification, PFPS components, and medication use) were similar for the 2 surgical groups except for 2 variables. Patients in the M-MVD group had slightly higher incidence of V3 pain, and the 2 groups differed in the date of surgery and hence in the length of follow-up (2.4 years for the M-MVD group and 1.3 years for the E-MVD group, $p<0.05$ ). There was a trend toward not finding neurovascular conflict at the time of surgery more frequently in the M-MVD than in the E-MVD group ( $11 \%$ vs $7 \%, p=0.052)$. Internal neurolysis was more often performed in the E-MVD group ( $26 \%$ vs $7 \%, p=0.001)$. The 2 groups did not significantly differ in the length of the MVD procedure (approximately 2 hours). Self-reported headaches at 1 month postoperatively were present in $21 \%$ of the patients in the M-MVD group versus $7 \%$ in the E-MVD group $(p=0.01)$. Pain outcomes at the most recent followup were equivalent, with patients reporting a 5 - to 6 -point $(70 \%-80 \%)$ improvement in pain intensity, a 5 -point $(85 \%)$ improvement in pain interference with ADLs, and a 6-point (85\%) improvement in interference with facial-specific ADLs. Actuarial freedom from pain recurrence was equivalent in the 2 groups, with $80 \%$ pain control at 3 years.

CONCLUSIONS Both the fully endoscopic MVD and the conventional M-MVD appear to provide patients with equivalent pain outcomes. Complication rates were also similar between the groups, with the exception of the rate of headaches, which was significantly lower in the E-MVD group 1 month postoperatively.

https://thejns.org/doi/abs/10.3171/2016.5.JNS1621

KEY WORDS microvascular decompression; trigeminal neuralgia; endoscope; minimally invasive surgery; facial pain; Brief Pain Inventory; functional neurosurgery

$\mathrm{T}$ HE microvascular decompression (MVD) procedure has been shown to be an effective and reliable procedure to treat patients with trigeminal neuralgia (TN). ${ }^{4}$ The technique has been honed in thousands of patients and is relatively safe with combined stroke and death rates of less than $0.3 \% .^{30}$ Improvements on the microscopic technique are therefore difficult to demonstrate. Endoscopic MVD (E-MVD) is a relatively new modification of the MVD procedure and has been performed as both an endoscope-assisted approach , $^{6,10,18,33,34,38,44}$ and as

ABBREVIATIONS ADL = activity of daily living; BNI = Barrow Neurological Institute; BPI = Brief Pain Inventory; E-MVD = endoscopic MVD; M-MVD = microscopic MVD; MVD = microvascular decompression; NVC = neurovascular conflict; PFPS = Penn Facial Pain Scale; TN = trigeminal neuralgia.

SUBMITTED January 13, 2016. ACCEPTED May 13, 2016.

INCLUDE WHEN CITING Published online July 29, 2016; DOI: 10.3171/2016.5.JNS1621. 


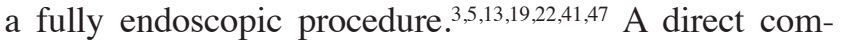
parison of E-MVD with microscopic MVD (M-MVD) involving validated outcome tools such as the Penn Facial Pain Scale (PFPS, formerly known as Brief Pain Inventory [BPI]-Facial) has not been reported. ${ }^{9,24,39}$ This study is the first direct comparison of bimanual microdissection techniques using either an endoscope or a microscope and involving modern pain-outcome assessment tools.

\section{Methods \\ Study Design}

The present investigation was a single-center, singlesurgeon (J.Y.K.L.), institutional review board-approved retrospective study. On the basis of Burchiel's classification scheme and of the International Headache Society definition of TN, we assigned patients to diagnostic categories. ${ }^{7,16}$ Only the patient's clinical history and classification of TN were used to determine appropriateness for surgery. MRI results were used only to exclude tumors, arteriovenous malformations, and other structural abnormalities, and the presence of neurovascular conflicts (NVCs) on MRI scans was not a criterion to determine appropriateness for surgery. Patients with either Burchiel Type 1 or Burchiel Type 2 TN were offered 1 of 3 procedures: MVD, percutaneous glycerol rhizotomy, or Gamma Knife radiosurgery. The results in the present study represent only those from a subset of patients who chose to undergo MVD.

\section{Surgical Procedures}

The surgeon performed 93 M-MVDs between 2006 and 2010. Thereafter, the surgeon transitioned from microscopic surgery to fully endoscopic surgery, which consisted of 14 endoscope-assisted operations in which the microscope was used as the primary visualization tool, and the endoscope was used as an adjunct to further visualize anatomy. ${ }^{13,22}$ Eventually, the microscope was no longer used, and a fully endoscopic surgery was employed. For purposes of analysis, the 14 endoscope-assisted procedures were included in the endoscopic arm for a total of 74 E-MVDs performed between 2010 and 2013. Most importantly, the E-MVDs involved the use of a pneumatic endoscope-holding arm, allowing the surgeon to work with both hands (Fig. 1). Further details of the technique have been described in previous studies. ${ }^{5,13,22}$ All cases from these previous reports on E-MVD are included in this series.

Briefly, the patient is placed in a lateral decubitus position, and a linear incision is made behind the ear. In all reported cases, a craniectomy was performed with a drill and Kerrison rongeurs. After the sigmoid and transverse sinuses are identified, a $\mathrm{C}$-shaped dural opening is created and flapped toward the sigmoid sinus (Fig. 2B). For E-MVD, the pneumatic arm is used to hold the endoscope, while bimanual dissection is performed underneath the 2.7-mm (outer diameter) endoscope. Careful attention is paid to keeping both a distal and proximal triangle to avoid clashing instruments as they are introduced into the cerebellopontine angle. The endoscope is always kept at the apex of the equilateral triangle (Fig. 2A). Bimanual dissection is generally preferred, but in

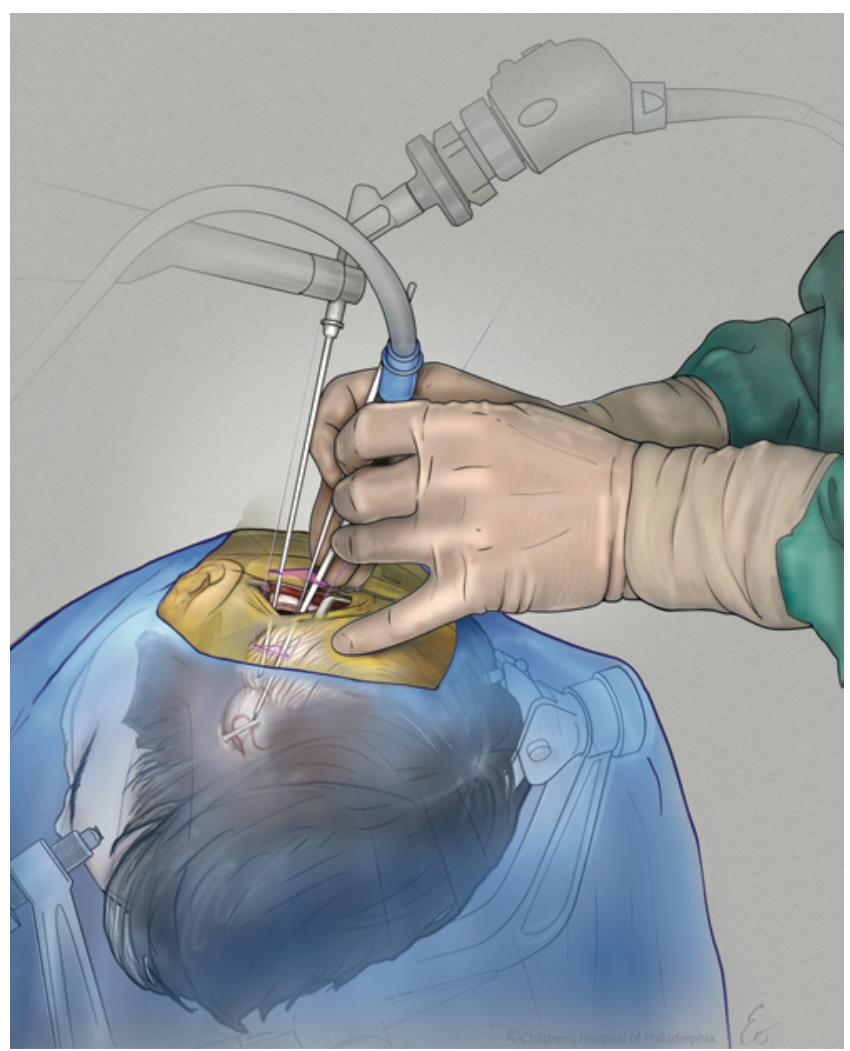

FIG. 1. Use of a pneumatic endoscope-holding arm allows the surgeon to work with both hands within the cerebellopontine angle. Artist Eo Trueblood. Copyright Stream Studios/The Children's Hospital of Philadelphia. Published with permission.

cases with a very prominent petrous tubercle, the senior surgeon sometimes resorted to 1-handed surgery to fit both the endoscope and a microdissection instrument into the tight confines of the cerebellopontine angle. In both E-MVD and M-MVD cases, dural closure was done primarily with silk sutures, with adjunct use of a dural collagen allograft. Bony closure was achieved with a titanium mesh plate (Synthes) cut to fit the bony defect for M-MVD procedures and, alternatively, with a bur hole cap for E-MVD cases (Fig. 2C).

\section{Outcome Assessments}

At the first clinic visit, patients completed an extensive questionnaire that included the PFPS (see Appendix). ${ }^{9,24}$ The PFPS measures 3 domains of pain: pain intensity, interference with activities of daily living (ADLs), and interference with facial function. ${ }^{9,24}$ An 11-point Likert scale (ranging from 0 to 10 ) is used to measure these domains. Follow-up phone calls were conducted by independent research assistants, using a standardized telephone script to achieve uniform outcome measures, and included a repeat PFPS assessment, in addition to the use of the Patient Global Impression of Change instrument, a 7-point ordinal scale consisting of the following ratings: "very much improved," "much improved," "minimally improved," "no change," "minimally worse," "much worse," and "very much worse." Additional questions concerned outcomes: 

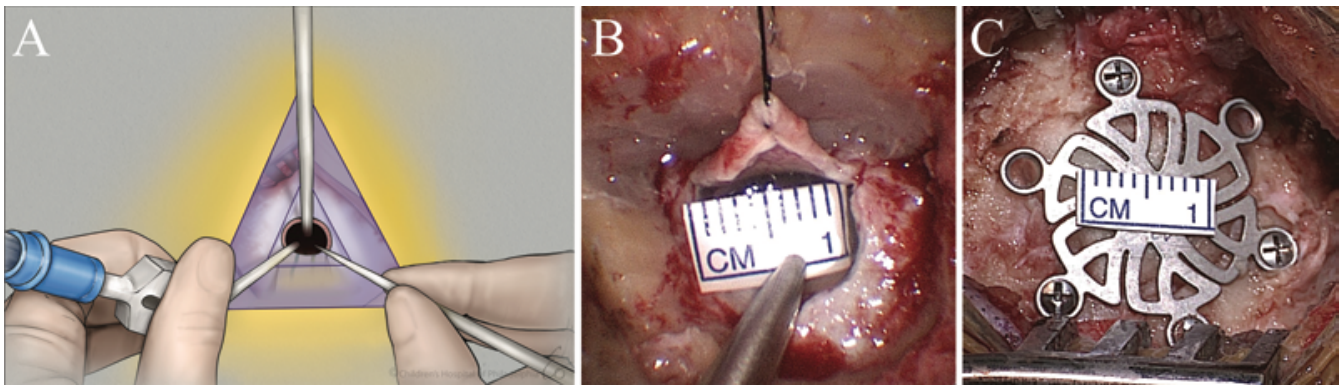

FIG. 2. A: The triangle method, with the endoscope parked at the apex, allows excellent microdissection at the base of the triangle through a smaller retrosigmoid bony exposure. Artist Eo Trueblood. Copyright Stream Studios/The Children's Hospital of Philadelphia. Published with permission. B: The dura mater has been opened over the cerebellar hemisphere and reflected toward the sigmoid sinus. C: A 17-mm bur hole cap is placed for closure of the bony defect.

"When did pain return to the preoperative level?" "Do you have headaches?" "Do you have dizziness?" The responses to these questions were entered into a database (Access, Microsoft Corp.), and exported to an Excel spreadsheet and imported for statistical analysis (STATA version 10, StataCorp LP).

\section{Statistical Analysis}

Two-tailed t-tests were used for continuous variables and chi-square tests for categorical variables. Actuarial analysis was performed with Kaplan-Meier techniques, and comparisons of pain recurrence curves were performed with the Cox model. In calculating pain recurrence, we asked patients "When did you experience your facial pain return?" The response was coded in years and months. Hence, any recurrence of facial pain at any time point was considered a "failure" for the purposes of the Cox regression analysis. We believed this to be a more stringent standard than pain scales such as the Barrow Neurological Institute (BNI) pain scale..$^{35}$

\section{Results}

\section{Patient Characteristics}

Patient demographics were well balanced between the E-MVD and M-MVD groups (Table 1). Overall, most of the patients in the present study were women (66.5\%), and their mean age was in the fifth decade of life. There was a trend toward more patients in the M-MVD group having Burchiel Type $1 \mathrm{TN}$ (88\% vs 79\%, p =0.11), a difference that could have biased the results toward better outcomes in the M-MVD group. ${ }^{32}$ The distribution of pain along the 3 branches of the trigeminal nerve was similar between the 2 groups, with overall a higher prevalence of V2 and V3 pain than of V1 pain. Curiously, there was a higher proportion of V3 pain in the M-MVD group than in the E-MVD group ( $71 \%$ vs $56 \%, p=0.04)$. In both groups, slightly more patients had right-sided pain than left-sided pain.

There was a trend toward the M-MVD group having undergone more previous procedures (including stereotactic radiosurgery and percutaneous injections, including sphenopalatine blocks) than the E-MVD group (36\% vs $24 \%$; $p=0.13)$. Most patients $(>80 \%)$ had been successfully treated with antiepileptic medications (carbam- azepine or oxcarbazepine) in the past, but only approximately $40 \%$ of patients continued to benefit from these medications at the time of surgery. In all 3 domains of the PFPS, the 2 groups were equally balanced with severe intensity and severe interference: pain intensity had a mean score of 8 at its worst, interfered with general ADLs with a mean score of 6 , and interfered with facial function

TABLE 1. Patient baseline characteristics

\begin{tabular}{|c|c|c|c|}
\hline \multirow[b]{2}{*}{ Variable } & \multicolumn{2}{|c|}{ MVD Treatment } & \multirow{2}{*}{$\begin{array}{c}p \\
\text { Value* }\end{array}$} \\
\hline & Endoscopic & Microscopic & \\
\hline No. of patients & 74 & 93 & \\
\hline Female (\%) & 68 & 65 & \\
\hline Mean age in yrs & 57 & 56 & \\
\hline Burchiel Type 1 TN (\%) & 79 & 88 & 0.11 \\
\hline Lt-sided pain (\%) & 47 & 40 & \\
\hline \multicolumn{4}{|l|}{$\begin{array}{l}\text { Trigeminal nerve pain distribu- } \\
\text { tion (\%) }\end{array}$} \\
\hline V1 & 26 & 33 & \\
\hline V2 & 82 & 80 & \\
\hline V3 & 56 & 71 & 0.04 \\
\hline Hx of previous procedures (\%) & 24 & 36 & 0.13 \\
\hline \multicolumn{4}{|l|}{ Antiepileptic medication (\%)† } \\
\hline Helped in the past & 83 & 84 & \\
\hline Helps currently & 38 & 43 & \\
\hline On medication at presentation & 87 & 88 & \\
\hline Surgery time period $\neq$ & 2010-2013 & $2006-2010$ & $<0.001$ \\
\hline \multicolumn{4}{|l|}{ PFPS score } \\
\hline General function (Items 1-7)§ & 6.4 & 6.2 & \\
\hline Facial function (Items 8-14)§ & 7.6 & 7.3 & \\
\hline Pain at its worst & 8.1 & 8.4 & \\
\hline Pain on average & 6.4 & 6.5 & \\
\hline \multicolumn{4}{|c|}{$\begin{array}{l}\text { Hx }=\text { history. } \\
\text { * Determined with chi-square test or t-test (only } p \text { values }<0.2 \text { are shown). } \\
\dagger \text { Antiepileptic medications included carbamazepine and oxcarbazepine. } \\
\text { † There was a slight overlap between the dates of surgery among patients } \\
\text { in the } 2 \text { groups because of a gradual transition in surgical technique from } \\
\text { microscope to endoscope. } \\
\S \text { See Appendix for details on the PFPS items. }\end{array}$} \\
\hline
\end{tabular}


TABLE 2. Operative findings*

\begin{tabular}{lccc}
\hline & \multicolumn{2}{c}{ MVD Treatment } & $p$ \\
\cline { 2 - 3 } \multicolumn{1}{c}{ Variable } & Endoscopic & Microscopic & Value† \\
\hline Arterial compression & 69 & 76 & \\
\hline SCA & 51 & 66 & 0.053 \\
\hline AICA & 12 & 16 & \\
\hline PICA & 0 & 0 & \\
\hline Dolichoectatic \& vertebrobasilar & 1 & 1 & \\
\hline Arteriole & 16 & 22 & 0.17 \\
\hline Venous compression & 41 & 44 & \\
\hline No vessel identified & 7 & 11 & 0.052 \\
\hline Neurolysis & 26 & 7 & 0.001 \\
\hline OR time (min) & 131 & 123 & \\
\hline Length of stay (days) & 2.8 & 2.6 & \\
\hline AlCA & & & \\
\hline
\end{tabular}

$\mathrm{AICA}=$ anterior inferior cerebellar artery; $\mathrm{OR}=$ operating room; $\mathrm{PICA}=$ posterior inferior cerebellar artery; SCA = superior cerebellar artery.

* Data represent percentages, unless indicated otherwise.

$\dagger$ Determined with chi-square test (only $p$ values $<0.2$ are shown)

with a mean score of 7. No statistically significant differences were observed in intraoperative findings of vessel compression between the 2 groups (Table 2). We noted a trend toward a higher incidence of nerve compression by the superior cerebellar artery in the M-MVD group (66\% vs $51 \% ; \mathrm{p}=0.053$ ). The E-MVD group was less likely to have no vessel identified as a source of the compression, but this difference (7\% vs $11 \%$ ) was not statistically significant $(\mathrm{p}=0.052)$.

The 2 groups differed in dates of surgery, and therefore the M-MVD group had a longer length of follow-up ( 2.4 vs 1.3 years, $\mathrm{p}<0.05$ ). Both duration of the procedure (just above 2 hours) and hospital length of stay (approximately 2.5 days) did not differ between the 2 groups.

\section{Complication Rates}

Complication rates were very low, and no deaths occurred in either group (Table 3). No cases complicated by cardiac morbidity, stroke, or hemiparesis were observed in the E-MVD group, and we noted only a slightly higher incidence of some of these major complications in the MMVD group. The only statistically significant difference between the groups was in the incidence of headaches at the 1-month follow-up: $21 \%$ of the M-MVD patients versus $7 \%$ of the E-MVD patients reported headaches ( $p=$ 0.01 ). This finding was not anticipated, and data regarding the intensity, character, or duration of the headaches were not available.

The M-MVD group had 2 complications that warrant attention. One patient had a postoperative stroke. This stroke was associated with a petrosal vein tear followed by bipolar coagulation of the vein and inadvertent coagulation of an adjacent pial artery. The stroke was identified when the patient reported gait ataxia, and a small infarct was found on diffusion-weighted MRI scans. Another patient underwent an uncomplicated M-MVD and immediately after surgery was noted to have facial paralysis that failed to resolve with time. For this patient, no changes in
TABLE 3. Postoperative complications*

\begin{tabular}{|c|c|c|c|}
\hline \multirow[b]{2}{*}{ Complication } & \multicolumn{2}{|c|}{ MVD Treatment } & \multirow{2}{*}{$\begin{array}{c}p \\
\text { Value† }\end{array}$} \\
\hline & Endoscopic & Microscopic & \\
\hline Death & 0 & 0 & \\
\hline Cardiac morbidity & 0 & 3 & \\
\hline Stroke & 0 & 1 & \\
\hline Hemiparesis & 0 & 0 & \\
\hline CSF leak & 1 & 1 & \\
\hline Facial paralysis & 0 & 1 & \\
\hline Hearing loss & 4 & 3 & \\
\hline Dizziness & 7 & 8 & \\
\hline Vertigo & 3 & 3 & \\
\hline Headaches (at 1-mo FU) & 7 & 21 & 0.01 \\
\hline Diplopia (at 1-mo FU) & 0 & 2 & 0.19 \\
\hline Facial numbness & 15 & 12.5 & \\
\hline
\end{tabular}

brainstem auditory evoked responses were observed during the surgery, and no specific cause of the facial palsy could be identified.

Notably, no statistically significant difference was observed in the incidence of new facial numbness, in spite of the more extensive use of internal neurolysis in the EMVD group than in the M-MVD group (26\% vs $7 \%$, $p=$ 0.001 ). Internal neurolysis is a technique typically used in the absence of NVC and involves the use of a round knife to dissect between the fascicles of the trigeminal nerve. ${ }^{20}$ Before adoption of this technique in $2009,{ }^{29}$ the surgeon would perform a partial sensory rhizotomy only rarely. ${ }^{12}$ Within both E-MVD and M-MVD groups, no statistically significant differences in pain outcomes, assessed with the PFPS, were detected between patients who underwent neurolysis and those who did not $(p>0.05)$. Likewise, no significant difference was detected in univariate Cox regression within each interventional group and with neurolysis as the independent variable $(\mathrm{p}=0.15)$.

\section{Outcomes}

At mean follow-up lengths of 2.4 and 1.3 years for the M-MVD and E-MVD groups, respectively, no statistically significant differences were observed in pain outcomes measured with the PFPS (Table 4). Patients improved by $5-6$ points $(70 \%-80 \%)$ in the domain of pain intensity, 5 points $(85 \%)$ with respect to interference with ADLs, and 6 points $(85 \%)$ for interference with facial function. These findings were validated by the Patient Global Impression of Change measure: no statistically significant difference was detected in the proportion of patients who reported "very much improved" or "much improved" in the 2 groups. Approximately 25\% of the patients remained on medications postoperatively. However, medications were broadly defined as any neuropathic pain medication that could have been used for a variety of indications (e.g., gabapentin for lumbar radiculopathy) and not specifically 
TABLE 4. Pain outcomes at last follow-up*

\begin{tabular}{ccc}
\hline & \multicolumn{2}{c}{ MVD Treatment } \\
\cline { 2 - 3 } & Endoscopic & Microscopic \\
\hline $\begin{array}{c}\text { Absolute change in PFPS score from } \\
\text { preop to postop (\% change) }\end{array}$ & & \\
\hline General function (Items 1-7) & $5.0(85)$ & $5.4(85)$ \\
\hline Facial function (Items 8-14) & $6.4(86)$ & $6.4(83)$ \\
\hline Pain at its worst & $6.2(73)$ & $6.4(78)$ \\
\hline Pain on average & $5.0(78)$ & $5.5(84)$ \\
\hline $\begin{array}{c}\text { Patient global impression of change in } \\
\text { pain (\%) }\end{array}$ & & \\
\hline $\begin{array}{c}\text { Very much improved } \\
\text { Very much improved \& much } \\
\text { improved }\end{array}$ & 78 & 80 \\
\hline $\begin{array}{c}\text { On neuropathic pain medications postop } \\
\text { (\%) }\end{array}$ & 28 & 22 \\
\hline
\end{tabular}

* No statistically significant differences in pain outcomes between the 2 surgical groups were detected (all $p$ values, determined with chi-square or t-tests, were $>0.2$ ).

for TN. Last, using the Cox model, we did not detect a statistically significant difference between the 2 groups in actuarial freedom from facial pain recurrence, and we observed $80 \%$ pain control at 3 years (Fig. 3 ).

\section{Discussion}

Microvascular decompression involving a microscope for magnification and visualization is a standard of care for patients with medication-refractory $\mathrm{TN} .{ }^{4}$ The use of the endoscope for MVD, however, remains a niche technique used by only a few surgeons. ${ }^{5,13,19,22,41}$ Indeed, most studies report using a hybrid technique that we refer to as endoscope-assisted MVD, ${ }^{33,34,44}$ in which the angled endoscope is used primarily as an adjunct to the microscope in examining local anatomy. The only study directly comparing M-MVD and E-MVD merely reported raw differences. ${ }^{19}$ Hence, the current investigation is the first to compare these 2 techniques with standard statistical methods and to use a reliable and validated outcome tool, the PFPS (formerly known as BPI-Facial). ${ }^{9,24,39}$

\section{Outcome Tools in TN Assessment}

In the absence of randomized clinical trials to provide evidence for decision making in the surgical management of TN, it is imperative to document outcomes after TN surgery in a systematic manner. Trigeminal neuralgia is a chronic pain condition; hence, the primary outcome variable is pain, ideally assessed as both its sensory (pain intensity) and reactive components (interference with daily life) in accordance with the consensus guidelines of pain study group initiatives such as the Initiative on Methods, Measurement, and Pain Assessment in Clinical Trials (IMMPACT). ${ }^{46}$ In a 2003 review, however, the authors note that of 222 articles, only 1 measured pain before surgical intervention, precluding analysis of the impact of the intervention on pain..$^{48} \mathrm{~A}$ more recent review of articles spanning the 2008-2010 period reported that only 13 studies of 56 used outcome measures. ${ }^{1}$ All but 2 of these studies used the BNI pain scale, ${ }^{35}$ which has been widely adopted because of its perceived simplicity of use, but has never been validated. Moreover, the BNI scale is a composite of 3 outcome variables (intensity of pain, medica-

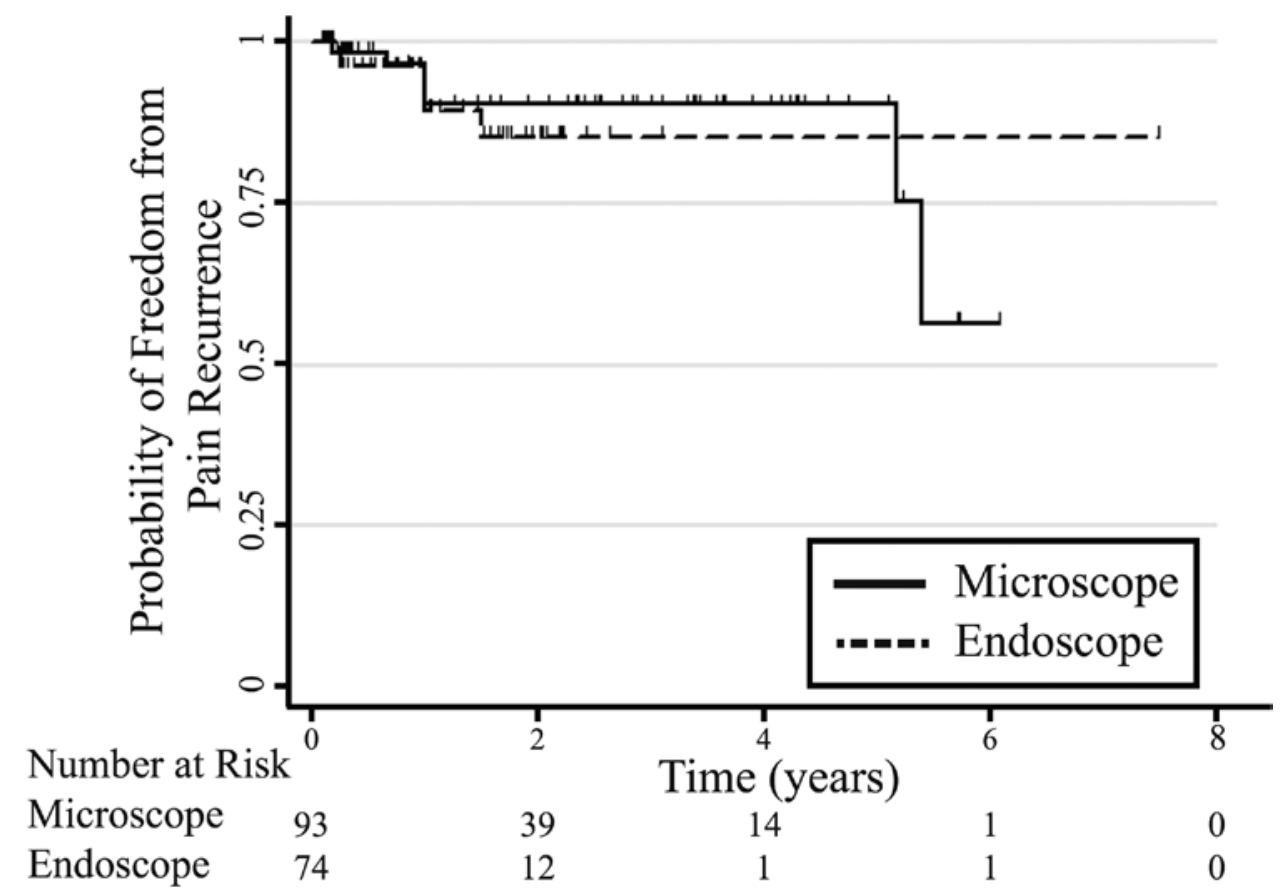

FIG. 3. Kaplan-Meier curve of freedom from severe pain among patients in the M-MVD (solid line) and E-MVD (dashed line) groups. 

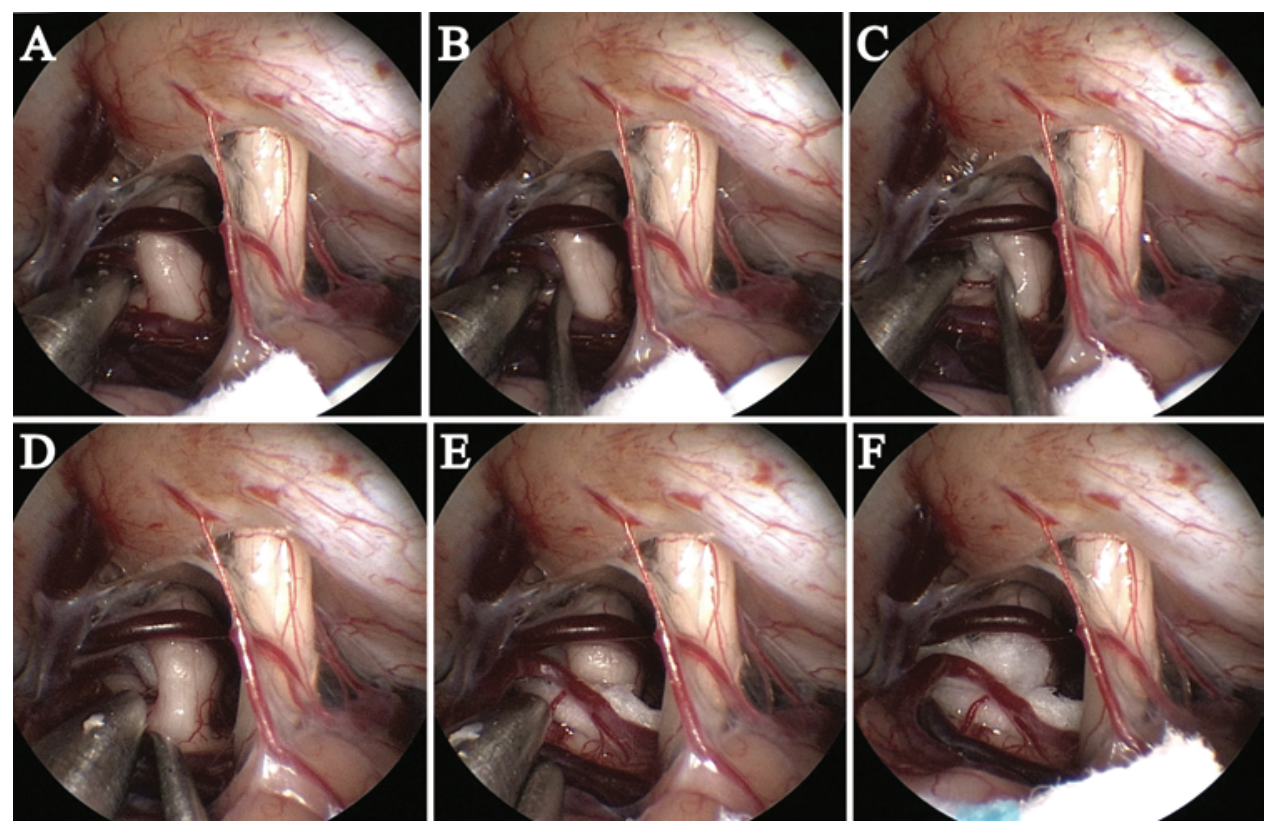

FIG. 4. Microvascular decompression of the left trigeminal nerve. An endoscopic view reveals compression of the trigeminal nerve laterally by the anterior inferior cerebellar artery, medially/cephalad by the superior cerebellar artery, and by a vein (A). Dissection of the anterior inferior cerebellar artery (B) and decompression from this vessel with Teflon (C), dissection of the superior cerebellar artery (D) and decompression from this vessel (E), and decompression from a vein (F).

tion use, and pain control with medications), and fails to encompass the effect of TN pain on quality of life (reactive component). The remaining 2 studies modified the BPI, 26,27 which was originally developed for cancer-specific pain and is currently widely used for a variety of pain etiologies. ${ }^{11,43}$ Although the BPI measures both the sensory and reactive components of pain, it does not cover symptoms specific to TN.

In 2010, the senior author of the present study (J.Y.K.L.) modified the BPI to create the PFPS and validated its use in the population of patients with TN. ${ }^{24}$ The PFPS measures 3 domains of pain (intensity, interference with general ADLs, and interference with facial-specific ADLs) and was shown to have reliable internal consistency. The minimum clinically important difference in pain outcomes for TN patients undergoing surgical intervention has also been defined for the PFPS. ${ }^{39}$ Researchers in another study used the PFPS to detect subtle differences in outcomes depending on the dose rate in Gamma Knife radiosurgery for $\mathrm{TN}^{25}$ and for which previous outcome tools such as the BNI scale may not have been sensitive enough. ${ }^{2}$ The PFPS has recently been endorsed by Zakrzewska and colleagues as the "essential outcome measure" for the systematic study of pain in patients with TN. ${ }^{1}$

Given these benefits, we employed the PFPS in the current study with the goal of determining whether E-MVD would lead to better outcomes than M-MVD. We report our findings in close adherence to the Surgical TN Score. ${ }^{1}$

\section{Endoscopic Microvascular Decompression}

In the present study, pain outcomes were measured before and after surgery with the validated PFPS. At baseline, the patients in the M-MVD and E-EVD groups were well matched in all 3 dimensions of the PFPS. The patients in both groups exhibited an improvement of 70\%-80\% in pain intensity, interference with general ADLs, and facialspecific ADLs. In addition, medication use dropped from approximately $80 \%$ to $20 \%$. No statistically significant differences in these outcomes were detected between the 2 groups; hence, our results indicate similar efficacy of MVD regardless of whether a microscope or endoscope was used. Likewise, actuarial freedom from severe pain recurrence was equivalent, with $80 \%$ pain control at the 3 -year follow-up for both groups.

The use of the endoscope for visualization and magnification resulted in higher rates of identification of $\mathrm{NVC}$ (Fig. 4). In up to $28 \%$ of cases, the offending vessels can be identified only with the panoramic view afforded by the endoscope. . $10,18,38,44$ Whether this improved visualization improves outcomes in TN surgery has not been studied. In the present study, NVC could not be visualized in $11 \%$ of M-MVDs and 7\% of E-MVDs, a difference that trended toward statistical significance. In spite of this trend toward improved visualization of NVC with the use of an endoscope, no difference in pain outcomes was observed between the 2 procedures.

One possible explanation, proposed by Burchiel, why improved visualization of NVC, and presumably higher rates of decompression, may not lead to better pain outcomes is that trigeminal NVC may not be necessary or sufficient for causing TN. Both Type 1 and 2 TNs have been shown to occur or reoccur without MRI evidence of neurovascular compression in $29 \%$ and $18 \%$ of cases, respectively. ${ }^{23}$ Moreover, MRI evidence of neurovascular compression was reported in $17 \%$ of trigeminal nerves in individuals without symptoms of TN. ${ }^{31}$ 
TABLE 5. Summary of the literature findings on postoperative headaches after a retrosigmoid approach

\begin{tabular}{|c|c|c|c|c|c|c|c|c|}
\hline \multirow[b]{2}{*}{ Authors \& Year } & \multirow{2}{*}{$\begin{array}{c}\text { Total No. of } \\
\text { Patients in Study }\end{array}$} & \multicolumn{7}{|c|}{ Percentage of Patients Reporting Postop Headaches at FU } \\
\hline & & $<1 \mathrm{mo}$ & $1 \mathrm{mo}$ & 3 mos & 6 mos & $1 \mathrm{yr}$ & $2 \mathrm{yrs}$ & 3 yrs \\
\hline \multicolumn{9}{|l|}{ Vestibular schwannoma } \\
\hline Hanson et al., 1998 & 228 & - & - & - & 15 & 13 & 15 & 12 \\
\hline Harner et al., 1993 & 331 & - & - & 77 & - & 47 & 19 & - \\
\hline Jackson et al., 2000 & 183 & - & - & 55 & 70 & 44 & 21 & - \\
\hline Ruckenstein et al., 1996 & 35 & - & - & - & 26 & 17 & - & - \\
\hline Ryzenman et al., 2005 & 527 & - & - & 93 & 83 & 76 & 71 & 66 \\
\hline Schaller \& Baumann, 2003 & 155 & - & - & 33 & 23 & 7 & 6 & - \\
\hline \multicolumn{9}{|l|}{ MVD } \\
\hline Lovely et al., 1999 & 318 & 60 & 29 & - & 17 & - & - & - \\
\hline Silverman et al., 2004 & 41 & - & - & 7 & 5 & 5 & - & - \\
\hline Present study & 167 & - & $14^{*}$ & - & - & - & - & - \\
\hline \multicolumn{9}{|l|}{ Vestibular schwannoma or MVD } \\
\hline Teo \& Eljamel, 2010 & 105 & 36 & - & 9 & 8 & 7 & - & - \\
\hline
\end{tabular}

Use of endoscopic techniques in MVD can shed further light on these fascinating investigations. For a subset of patients who underwent surgical exploration, Lee et al. reported that the sensitivity of MRI for predicting NVC visualized with the microscope was $96 \%$ for both Type 1 and 2 TNs, and the specificity was $90 \%$ and $66 \%$, respectively. ${ }^{23}$ The use of the endoscope, that is, higher rates of NVC visualization than with the microscope, would most likely decrease the number of false-negative NVCs on MRI scans, that is, decrease the specificity of MRI. In other words, use of an endoscope in TN surgery could show that the rates of NVC are actually higher than those reported by Lee et al. ${ }^{23}$ Moreover, internal neurolysis is typically performed only in the absence of NVC..$^{20}$ Hence, improved visualization of the cerebellopontine angle with the endoscope allows the surgeon to more confidently rule out NVC, thereby aiding surgical decision making.

The results of the present study show that primary outcomes after E-MVD are not inferior to those of the more established M-MVD. As discussed, E-MVD also has the benefit of improved visualization of the cerebellopontine angle (Fig. 4), in addition to theoretically allowing for a smaller bony exposure and dural opening (Fig. 2B). Its disadvantages include a $2 \mathrm{D}$ view lacking a depth of field, the endoscope itself occupying space within a small surgical area, and heat generation at the tip of the endoscope that could potentially harm adjacent structures.

\section{Postoperative Headaches}

Postoperative headaches are a well-recognized complication after surgery via a retrosigmoid approach, which results in a higher incidence of these adverse effects than with other approaches. ${ }^{21}$ In a large series of 318 M-MVD patients, the rate of headaches 1 month postoperatively was $28.8 \%,{ }^{28}$ which is similar to the $21 \%$ incidence observed among patients in our M-MVD group.

Interestingly, the incidence of postoperative headaches at 1 month postoperatively was lower in the E-MVD group, at $7 \%$ versus $21 \%$ in the M-MVD group. Previous E-MVD case series have not examined postoperative headaches. ${ }^{3,19,41,47}$ Because the present study was not designed to more closely investigate the incidence of postoperative headaches, we did not have information about their intensity, character, or duration. However, it is clear from the existing literature on retrosigmoid approaches that the headache incidence is highest immediately after the surgery and gradually improves over time (Table 5); therefore, it is safe to assume that headaches will gradually resolve over time in both groups.

Possible etiologies of postoperative headaches after surgery involving a retrosigmoid approach include adherence of scalp and muscles to the dura, aseptic meningitis from bone dust, injury to occipital nerves, and neck spasms. ${ }^{8}$ In the current series, all patients underwent titanium cranioplasty either with a $15 / 17-\mathrm{mm}$ bur hole cap in patients in the E-MVD group (Fig. 2C) or with a larger mesh plate that was cut and contoured to fit the bony defect in patients in the M-MVD group. Hence, one possible explanation for our finding is the size of the bony exposure in combination with a larger scalp incision and muscle dissection that may have increased the likelihood of injury to the occipital nerves and of postoperative neck spasms. Indeed, in a study primarily comparing the incidence of postoperative headaches between patients who underwent craniotomy or craniectomy for a retrosigmoid approach, the authors found that the greatest predictor of headaches in craniotomy patients is the size of the bone flap. ${ }^{45}$ Using logistic regression, we calculated an odds ratio of 7.5 in favor of a smaller flap $(<3 \mathrm{~cm})$ over a larger flap $(3-6 \mathrm{~cm})$ for reducing the risk for headaches.

\section{Study Limitations}

Although the PFPS is patient scored and was prospectively administered, the design of the present study was 
retrospective and nonblinded. The patient sample represented the practice of a single neurosurgeon at a tertiary referral center and therefore may lack generalizability to other practice settings. Longitudinal data were acquired at the 1-month follow-up, but during the subsequent period, the follow-up intervals were not standardized. A better study design would have mandated phone calls at serial time points after surgery, such as at yearly intervals. Last, postoperative headaches were assessed only at the 1-month follow-up.

\section{Conclusions}

The Penn Facial Pain Scale, a novel, quantitative, and validated outcome tool was employed to assess whether patients with TN statistically significantly differed in pain outcomes after E-MVD or conventional M-MVD performed by the same surgeon. The results of the PFPS assessment and Kaplan-Meier techniques did not indicate any significant differences in TN pain outcomes between the 2 MVD groups. Endoscope use, however, did result in a statistically significant decrease in the incidence of headaches 1 month after surgery, suggesting that use of E-MVD may be favorable for patients in the hands of appropriately trained surgeons. All other complications were indistinguishable between the 2 groups. The explanation for the lower incidence of headaches with E-MVD is likely multifactorial and could have resulted from a smaller bony exposure, muscle dissection, and scalp incision. Future studies could explore these possible explanations for decreased postoperative headaches with E-MVD.

\section{Acknowledgments}

We thank Peter Jannetta, MD, whose lifetime pioneering contributions have cured countless patients. Fortunately, he spent his career teaching neurosurgeons to carry on the torch of microvascular decompression. We also acknowledge the contributions of the late Daniel Pieper, MD, whose early death has robbed patients and neurosurgeons of a generous technical leader. We also thank Hae Dong Jho, MD, $\mathrm{PhD}$, who is the visionary endoscopic surgeon whose technical virtuosity has resulted in many minimally invasive revolutions that continue to reverberate throughout neurosurgery.

\section{References}

1. Akram H, Mirza B, Kitchen N, Zakrzewska JM: Proposal for evaluating the quality of reports of surgical interventions in the treatment of trigeminal neuralgia: the Surgical Trigeminal Neuralgia Score. Neurosurg Focus 35(3):E3, 2013

2. Arai Y, Kano H, Lunsford LD, Novotny J Jr, Niranjan A, Flickinger JC, et al: Does the Gamma Knife dose rate affect outcomes in radiosurgery for trigeminal neuralgia? J Neurosurg 113 Suppl:168-171, 2010

3. Artz GJ, Hux FJ, Larouere MJ, Bojrab DI, Babu S, Pieper DR: Endoscopic vascular decompression. Otol Neurotol 29:995-1000, 2008

4. Barker FG II, Jannetta PJ, Bissonette DJ, Larkins MV, Jho HD: The long-term outcome of microvascular decompression for trigeminal neuralgia. N Engl J Med 334:1077-1083, 1996

5. Bohman LE, Pierce J, Stephen JH, Sandhu S, Lee JYK: Fully endoscopic microvascular decompression for trigeminal neuralgia: technique review and early outcomes. Neurosurg Focus 37(4):E18, 2014

6. Broggi M, Acerbi F, Ferroli P, Tringali G, Schiariti M, Broggi G: Microvascular decompression for neurovascular conflicts in the cerebello-pontine angle: which role for endoscopy? Acta Neurochir (Wien) 155:1709-1716, 2013

7. Burchiel KJ: A new classification for facial pain. Neurosurgery 53:1164-1167, 2003

8. Catalano PJ, Jacobowitz O, Post KD: Prevention of headache after retrosigmoid removal of acoustic tumors. Am J Otol 17:904-908, 1996

9. Chen HI, Lee JYK: The measurement of pain in patients with trigeminal neuralgia. Clin Neurosurg 57:129-133, 2010

10. Chen MJ, Zhang WJ, Yang C, Wu YQ, Zhang ZY, Wang Y: Endoscopic neurovascular perspective in microvascular decompression of trigeminal neuralgia. J Craniomaxillofac Surg 36:456-461, 2008

11. Cleeland CS, Ryan KM: Pain assessment: global use of the Brief Pain Inventory. Ann Acad Med Singapore 23:129138,1994

12. Goodwin CR, Yang JX, Bettegowda C, Hwang B, James C, Biser A, et al: Glycerol rhizotomy via a retrosigmoid approach as an alternative treatment for trigeminal neuralgia. Clin Neurol Neurosurg 115:2454-2456, 2013

13. Halpern CH, Lang SS, Lee JYK: Fully endoscopic microvascular decompression: our early experience. Minim Invasive Surg 2013:739432, 2013

14. Hanson MB, Glasscock ME III, Brandes JL, Jackson CG: Medical treatment of headache after suboccipital acoustic tumor removal. Laryngoscope 108:1111-1114, 1998

15. Harner SG, Beatty CW, Ebersold MJ: Headache after acoustic neuroma excision. Am J Otol 14:552-555, 1993

16. Headache Classification Subcommittee of the International Headache Society: The International Classification of Headache Disorders: 2nd edition. Cephalalgia 24 (Suppl 1):9-160, 2004

17. Jackson CG, McGrew BM, Forest JA, Hampf CR, Glasscock ME III, Brandes JL, et al: Comparison of postoperative headache after retrosigmoid approach: vestibular nerve section versus vestibular schwannoma resection. Am J Otol 21:412-416, 2000

18. Jarrahy R, Berci G, Shahinian HK: Endoscope-assisted microvascular decompression of the trigeminal nerve. Otolaryngol Head Neck Surg 123:218-223, 2000

19. Kabil MS, Eby JB, Shahinian HK: Endoscopic vascular decompression versus microvascular decompression of the trigeminal nerve. Minim Invasive Neurosurg 48:207-212, 2005

20. Ko AL, Ozpinar A, Lee A, Raslan AM, McCartney S, Burchiel KJ: Long-term efficacy and safety of internal neurolysis for trigeminal neuralgia without neurovascular compression. J Neurosurg 122:1048-1057, 2015

21. Koperer H, Deinsberger W, Jödicke A, Böker DK: Postoperative headache after the lateral suboccipital approach: craniotomy versus craniectomy. Minim Invasive Neurosurg 42:175-178, 1999

22. Lang SS, Chen HI, Lee JYK: Endoscopic microvascular decompression: a stepwise operative technique. ORL J Otorhinolaryngol Relat Spec 74:293-298, 2012

23. Lee A, McCartney S, Burbidge C, Raslan AM, Burchiel KJ: Trigeminal neuralgia occurs and recurs in the absence of neurovascular compression. J Neurosurg 120:1048-1054, 2014

24. Lee JYK, Chen HI, Urban C, Hojat A, Church E, Xie SX, et al: Development of and psychometric testing for the Brief Pain Inventory-Facial in patients with facial pain syndromes. J Neurosurg 113:516-523, 2010

25. Lee JYK, Sandhu S, Miller D, Solberg T, Dorsey JF, AlonsoBasanta M: Higher dose rate Gamma Knife radiosurgery may provide earlier and longer-lasting pain relief for patients with trigeminal neuralgia. J Neurosurg 123:961-968, 2015

26. Little AS, Shetter AG, Shetter ME, Bay C, Rogers CL: Longterm pain response and quality of life in patients with typical 
trigeminal neuralgia treated with Gamma Knife stereotactic radiosurgery. Neurosurgery 63:915-924, 2008

27. Little AS, Shetter AG, Shetter ME, Kakarla UK, Rogers CL: Salvage Gamma Knife stereotactic radiosurgery for surgically refractory trigeminal neuralgia. Int J Radiat Oncol Biol Phys 74:522-527, 2009

28. Lovely TJ, Lowry DW, Jannetta PJ: Functional outcome and the effect of cranioplasty after retromastoid craniectomy for microvascular decompression. Surg Neurol 51:191-197, 1999

29. Ma Z, Li M: "Nerve combing" for trigeminal neuralgia without vascular compression: report of 10 cases. Clin J Pain 25:44-47, 2009

30. McLaughlin MR, Jannetta PJ, Clyde BL, Subach BR, Comey $\mathrm{CH}$, Resnick DK: Microvascular decompression of cranial nerves: lessons learned after 4400 operations. J Neurosurg 90:1-8, 1999

31. Miller JP, Acar F, Hamilton BE, Burchiel KJ: Radiographic evaluation of trigeminal neurovascular compression in patients with and without trigeminal neuralgia. J Neurosurg 110:627-632, 2009

32. Miller JP, Magill ST, Acar F, Burchiel KJ: Predictors of longterm success after microvascular decompression for trigeminal neuralgia. J Neurosurg 110:620-626, 2009

33. Miyazaki H, Deveze A, Magnan J: Neuro-otologic surgery through minimally invasive retrosigmoid approach: endoscope assisted microvascular decompression, vestibular neurotomy, and tumor removal. Laryngoscope 115:1612-1617, 2005

34. Rak R, Sekhar LN, Stimac D, Hechl P: Endoscope-assisted microsurgery for microvascular compression syndromes. Neurosurgery 54:876-883, 2004

35. Rogers CL, Shetter AG, Fiedler JA, Smith KA, Han PP, Speiser BL: Gamma Knife radiosurgery for trigeminal neuralgia: the initial experience of The Barrow Neurological Institute. Int J Radiat Oncol Biol Phys 47:1013-1019, 2000

36. Ruckenstein MJ, Harris JP, Cueva RA, Prioleau G, Alksne $\mathrm{J}$ : Pain subsequent to resection of acoustic neuromas via suboccipital and translabyrinthine approaches. Am J Otol 17:620-624, 1996

37. Ryzenman JM, Pensak ML, Tew JM Jr: Headache: a quality of life analysis in a cohort of 1,657 patients undergoing acoustic neuroma surgery, results from the acoustic neuroma association. Laryngoscope 115:703-711, 2005

38. Sandell T, Ringstad GA, Eide PK: Usefulness of the endoscope in microvascular decompression for trigeminal neuralgia and MRI-based prediction of the need for endoscopy. Acta Neurochir (Wien) 156:1901-1909, 2014

39. Sandhu SK, Halpern CH, Vakhshori V, Mirsaeedi-Farahani K, Farrar JT, Lee JYK: Brief pain inventory-facial minimum clinically important difference. J Neurosurg 122:180190,2015

40. Schaller B, Baumann A: Headache after removal of vestibular schwannoma via the retrosigmoid approach: a long-term follow-up-study. Otolaryngol Head Neck Surg 128:387395,2003
41. Setty P, Volkov AA, D'Andrea KP, Pieper DR: Endoscopic vascular decompression for the treatment of trigeminal neuralgia: clinical outcomes and technical note. World Neurosurg 81:603-608, 2014

42. Silverman DA, Hughes GB, Kinney SE, Lee JH: Technical modifications of suboccipital craniectomy for prevention of postoperative headache. Skull Base 14:77-84, 2004

43. Tan G, Jensen MP, Thornby JI, Shanti BF: Validation of the Brief Pain Inventory for chronic nonmalignant pain. J Pain 5:133-137, 2004

44. Teo C, Nakaji P, Mobbs RJ: Endoscope-assisted microvascular decompression for trigeminal neuralgia: technical case report. Neurosurgery 59:ONSE489-ONSE490, 2006

45. Teo MK, Eljamel MS: Role of craniotomy repair in reducing postoperative headaches after a retrosigmoid approach. Neurosurgery 67:1286-1292, 2010

46. Turk DC, Dworkin RH, Allen RR, Bellamy N, Brandenburg $\mathrm{N}$, Carr DB, et al: Core outcome domains for chronic pain clinical trials: IMMPACT recommendations. Pain 106:337345, 2003

47. Yadav YR, Parihar V, Agarwal M, Sherekar S, Bhatele P: Endoscopic vascular decompression of the trigeminal nerve. Minim Invasive Neurosurg 54:110-114, 2011

48. Zakrzewska JM, Lopez BC: Quality of reporting in evaluations of surgical treatment of trigeminal neuralgia: recommendations for future reports. Neurosurgery 53:110-122, 2003

\section{Disclosures}

This work was partially funded by an educational grant from StorzTM.

\section{Author Contributions}

Conception and design: Lee, Petrov. Acquisition of data: Lee, Pierce, Sandhu, Petrov. Analysis and interpretation of data: all authors. Drafting the article: Lee, Yang. Critically revising the article: Lee, Petrov, Yang. Reviewed submitted version of manuscript: all authors. Approved the final version of the manuscript on behalf of all authors: Lee. Statistical analysis: Lee, Yang. Administrative/technical/material support: Lee. Study supervision: Lee.

\section{Supplemental Information \\ Online-Only Content}

Supplemental material is available with the online version of the article.

$$
\text { Appendix. https://thejns.org/doi/suppl/10.3171/2016.5.JNS1621. }
$$

\section{Correspondence}

John Y. K. Lee, Department of Neurosurgery, University of Pennsylvania, 235 South Eighth St., Philadelphia, PA 19106. email: leejohn@uphs.upenn.edu. 